\title{
Synthesis of unnatural $\alpha$-amino esters using ethyl nitroacetate and condensation or cycloaddition reactions
}

\author{
Glwadys Gagnot ${ }^{1,2,3}$, Vincent Hervin ${ }^{1,2}$, Eloi P. Coutant ${ }^{1,2}$, Sarah Desmons ${ }^{1,2}$, \\ Racha Baatallah ${ }^{1,2}$, Victor Monnot ${ }^{1,2}$ and Yves L. Janin ${ }^{* 1,2}$
}

\section{Full Research Paper}

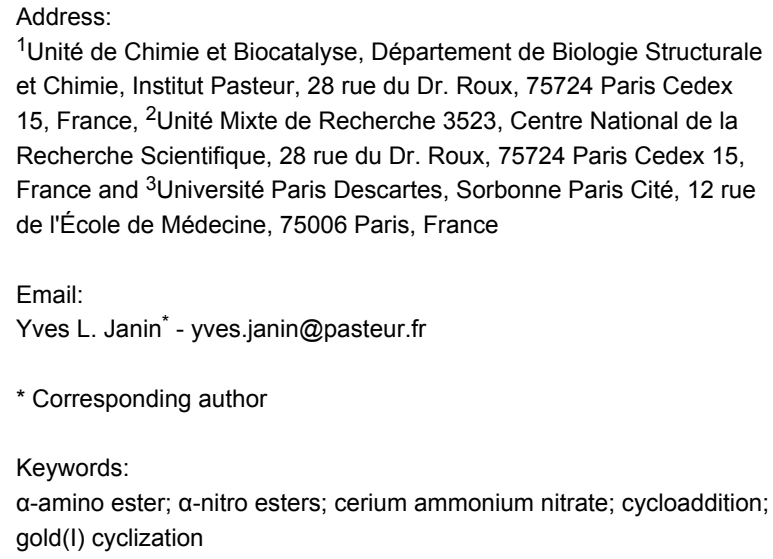

${ }^{1}$ Unité de Chimie et Biocatalyse, Département de Biologie Structurale et Chimie, Institut Pasteur, 28 rue du Dr. Roux, 75724 Paris Cedex 15, France, ${ }^{2}$ Unité Mixte de Recherche 3523, Centre National de la Recherche Scientifique, 28 rue du Dr. Roux, 75724 Paris Cedex 15, France and ${ }^{3}$ Université Paris Descartes, Sorbonne Paris Cité, 12 rue de l'École de Médecine, 75006 Paris, France

\section{Email:}

Yves L. Janin * - yves.janin@pasteur.fr

${ }^{*}$ Corresponding author

\section{Keywords:}

$\alpha$-amino ester; $\alpha$-nitro esters; cerium ammonium nitrate; cycloaddition; gold(I) cyclization

\author{
Beilstein J. Org. Chem. 2018, 14, 2846-2852. \\ doi:10.3762/bjoc. 14.263
}

Received: 09 August 2018

Accepted: 26 October 2018

Published: 15 November 2018

Associate Editor: B. Stoltz

(c) 2018 Gagnot et al.; licensee Beilstein-Institut. License and terms: see end of document.

\begin{abstract}
We report here on the use of ethyl nitroacetate as a glycine template to produce $\alpha$-amino esters. This started with a study of its condensation with various arylacetals to give ethyl 3-aryl-2-nitroacrylates followed by a reduction $\left(\mathrm{NaBH}_{4}\right.$ and then zinc/ $\left.\mathrm{HCl}\right)$ into $\alpha$-amino esters. The scope of this method was explored as well as an alternative with arylacylals instead. We also focused on various [2+3] cycloadditions, one leading to a spiroacetal, which led to the undesired ethyl 5-(benzamidomethyl)isoxazole-3carboxylate. The addition of ethyl nitroacetate on a 5-methylene-4,5-dihydrooxazole using cerium(IV) ammonium nitrate was also explored and the synthesis of other oxazole-bearing $\alpha$-amino esters was achieved using gold(I) chemistry.
\end{abstract}

\section{Introduction}

In the course of our work on an original synthesis of imidazo[1,2-a]pyrazin-3(7H)-one luciferins [1], a large variety of racemic $\alpha$-amino esters was required to prepare a corresponding array of analogues. As we reviewed recently, nitroacetates are amongst the principal glycine templates used to prepare $\alpha$-amino esters 1 [2]. The retrosynthetic pathway depicted in Scheme 1 requires a reduction of ethyl nitroacrylates $\mathbf{2}$, which are made from condensation reactions between aldehydes 3 or acetals 5 and ethyl nitroacetate (4). However, the high yield condensations with aldehydes 3 which were reported for some examples $[3,4]$ require more than stoichiometric amounts of titanium tetrachloride thus leading to considerable amounts of metal-containing chemical waste. Moreover, far lower yields were reported in many other instances when using this reagent 


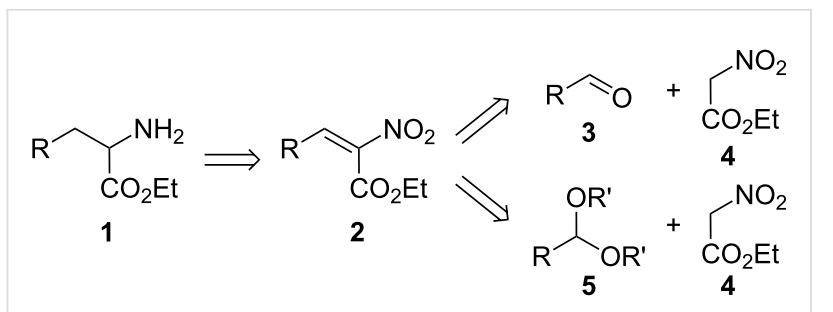

Scheme 1: $\alpha$-Amino esters from ethyl nitroacetate (4).

$[5,6]$. In an attempt to improve the generality of this synthetic pathway and diminish its requirement for metals, we studied some alternatives, such as the condensations between ethyl nitroacetate (4) and acetals 5 or other approaches further described in the following.

\section{Results and Discussion}

As depicted in Table 1, we first studied the scope of the condensation between ethyl nitroacetate (4) and aryldimethylacetals $\mathbf{5 a}-\mathbf{s}$ which are easily obtained in situ from the corresponding arylaldehydes $\mathbf{3 a}-\mathbf{s}$. As seen by ${ }^{1} \mathrm{H}$ NMR monitoring, the treatment of arylaldehydes $\mathbf{3 a}-\mathbf{s}$ with trimethyl orthoformate and an acid-bearing resin in dry methanol led to full conversion into the corresponding acetals $\mathbf{5 a}-\mathbf{s}$. Then, as reported [7,8], heating the crude acetals $\mathbf{5 a}-\mathbf{s}$ and ethyl nitroacetate (4) in the presence of acetic anhydride afforded a mixture of compounds containing variable amounts of the expected acrylates $\mathbf{2 a}-\mathbf{s}$. No attempts were made to purify these as they were immediately subjected to a reduction of its double bond using sodium borohydride $[9,10]$ in refluxing isopropanol in order to properly isolate the corresponding $\alpha$-nitro esters $\mathbf{6 a}-\mathbf{s}$. Isopropanol was used instead of ethanol in order to decrease the incidence of a recurrent side product arising from a decarboxylation or a retro condensation of the partially reduced ester function (this side product was characterized in ${ }^{1} \mathrm{H}$ NMR by two triplets at $4.6 \mathrm{ppm}$ and $3.4 \mathrm{ppm}$, but eluded our purification efforts). Moreover, one minute in refluxing isopropanol was found to be sufficient to complete the reduction especially for the fairly insoluble acrylate $\mathbf{2 e}$, and also avoided most of the undesired transesterification byproducts that could form upon long reaction times. As seen in Table 1, modest yields of compounds $\mathbf{6 a}-\mathbf{i}$ were isolated anyway, especially for meta-substituted phenyl-bearing products $\mathbf{6 c}, \mathbf{6} \mathbf{f}$ and $\mathbf{6 h}$. Even if the reduction was less than perfect, the low yields originate from the initial condensation between acetals 5 and $\mathbf{4}$. Indeed, when considering the phenyl derivative of $\mathbf{6 a}$, a sobering $35 \%$ isolated yield was obtained, in stark contrast to the reported $95 \%$ yield published in 1980 [7]. In our hands, ${ }^{1} \mathrm{H}$ NMR analysis of the crude condensation product pointed out the occurrence of the intermediate acrylate 2a along with a large amount of methyl benzoate, a well-known side product in this reaction $[7,8]$. From the aryl
Table 1: Synthesis and reductions of $\alpha$-nitro acrylates into $\alpha$-amino esters.
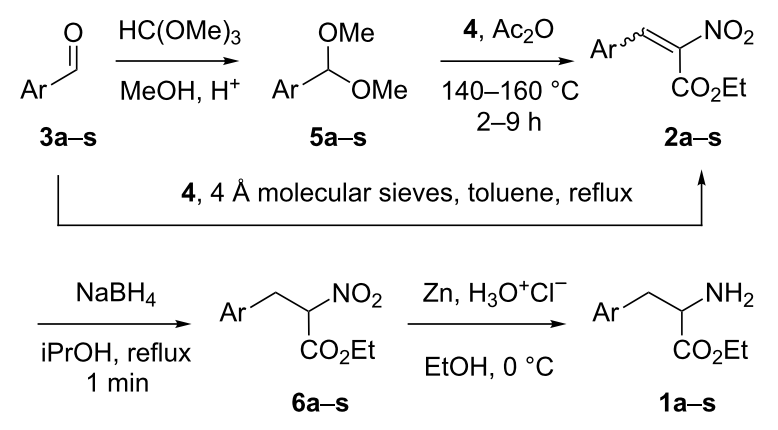

\begin{tabular}{llll}
\hline $\operatorname{Ar}$ & $\% 6^{\mathrm{a}}$ & $\% 6^{\mathrm{b}}$ & $\% 1$ \\
\hline
\end{tabular}

\begin{tabular}{|c|c|c|c|c|}
\hline $\mathbf{a}$ & $\mathrm{C}_{6} \mathrm{H}_{5}$ & $35^{c}$ & & - \\
\hline b & $2-\mathrm{MeOC}_{6} \mathrm{H}_{4}$ & 53 & & 90 \\
\hline c & $3-\mathrm{MeOC}_{6} \mathrm{H}_{4}$ & 21 & & 92 \\
\hline d & $4-\mathrm{MeOC}_{6} \mathrm{H}_{4}$ & 55 & & 95 \\
\hline e & $4-\mathrm{BnOC}_{6} \mathrm{H}_{4}$ & 51 & & 67 \\
\hline f & $3-\mathrm{MeC}_{6} \mathrm{H}_{4}$ & 16 & & 80 \\
\hline g & $2-\mathrm{FC}_{6} \mathrm{H}_{4}$ & 6 & & 94 \\
\hline h & $3-\mathrm{FC}_{6} \mathrm{H}_{4}$ & 0.9 & & - \\
\hline i & $4-\mathrm{FC}_{6} \mathrm{H}_{4}$ & 13 & & 94 \\
\hline j & $2-\mathrm{CF}_{3} \mathrm{C}_{6} \mathrm{H}_{4}$ & $0^{d}$ & & - \\
\hline k & $3-\mathrm{CF}_{3} \mathrm{C}_{6} \mathrm{H}_{4}$ & $<5^{d}$ & & - \\
\hline I & $4-\mathrm{CF}_{3} \mathrm{C}_{6} \mathrm{H}_{4}$ & $<5^{d}$ & & - \\
\hline m & 2-pyridyl & $0^{d}$ & & - \\
\hline $\mathbf{n}$ & furan-2-yl & 27 & $38 / 48^{e} / 70^{f}$ & 94 \\
\hline 0 & furan-3-yl & - & 34 & 88 \\
\hline $\mathbf{p}$ & 5-methyl-furan-2-yl & 60 & - & 75 \\
\hline $\mathbf{q}$ & 5-ethyl-furan-2-yl & 39 & - & 56 \\
\hline $\mathbf{r}$ & 4,5-dimethyl-furan-2-yl & $<20$ & $46^{e}$ & 79 \\
\hline $\mathbf{s}$ & thiophen-2-yl & 33 & - & 58 \\
\hline
\end{tabular}

alsolated yield from $3 \mathbf{a}-\mathbf{s}$, via acetals $\mathbf{5 a - s}$. b/solated yield via the direct condensation between $3 \mathbf{a}-\mathbf{s}$ and 4 . ${ }^{\mathrm{c}} 39 \%$ yield from (diethoxymethyl)benzene. ${ }^{\mathrm{d} A s}$ seen by ${ }^{1} \mathrm{H}$ NMR analysis. ${ }^{\mathrm{e}}$ Using $\mathrm{NaBH}_{3} \mathrm{CN}$; see text. 'Also using $\mathrm{NaBH}_{3} \mathrm{CN}$ but from pure $2 \mathbf{n}$; see text.

acetals $5 \mathrm{~g}-\mathbf{l}$ featuring electron-withdrawing groups, low to nondetectable amounts of the condensations products $2 \mathrm{~g}-\mathbf{I}$ were observed by ${ }^{1} \mathrm{H}$ NMR analysis, and this was reflected in the isolated yield of the corresponding $\alpha$-nitroesters $6 \mathbf{g}-\mathbf{i}$ as well as the lack of compounds $\mathbf{6 j - 1}$. Similarly, no condensation was observed when starting with the pyridyl-bearing acetal $\mathbf{5 m}$. These disappointing results are plausibly due to two factors: (i) As mentioned above, the condensation of ethyl nitroacetate (4) with aryl acetals 5 takes place along with an O-alkylation reaction which leads, via a rearrangement, to the corresponding aryl ester byproduct $[7,8]$. The proportion between the C-alkylation (leading to the expected acrylate) and this $\mathrm{O}$-alkylation is most certainly governed by the electronic effects of the substituent on the aryl group. Indeed, the best overall yields are observed 
when starting from the electronically similar 2-methoxy acetal $\mathbf{5 b}$ or the 4-methoxy analog $\mathbf{5 d}$, as well as the 4-benzyloxy acetal 5e. (ii) Secondly, the reduction of acrylates $\mathbf{2} \mathbf{a}-\mathbf{s}$ to compounds $\mathbf{6 a}-\mathbf{s}$ was achieved with sodium borohydride and the resulting basic conditions could be detrimental to the stability of some of these $\alpha$-nitro acrylates. In the past, such reductions have been achieved under fairly uncommon conditions $\left(\mathrm{NaBH}_{4}\right.$ in a mixture of isopropanol and chloroform over a large proportion of silica gel) $[11,12]$. However, when tried, no real overall improvements were observed with these conditions. Other series of trials were made to improve the overall yields of the furan-bearing $\alpha$-nitro esters $\mathbf{6 n}-\mathbf{r}$. We first tried to avoid the preparation of the acetals $\mathbf{5 n}$ or $\mathbf{5 0}$ and used the previously reported direct condensation between furfural (3n) and ethyl nitroacetate (4) [13]. Unfortunately, we could not reproduce the 95\% yield reported for compound $\mathbf{2 n}$, and under a thoroughly inert atmosphere (as advised) we obtained $48-53 \%$ isolated yields at best. In any case, this approach did shorten the synthetic pathway by one step and upon the reduction of the resulting acrylates 2 n or 20 using sodium borohydride, the $\alpha$-nitro esters 6n and 60 were isolated in the rather modest yields indicated in Table 1. We then focused on the model reduction of acrylate $\mathbf{2 n}$ into $6 \mathbf{n}$. Since all our attempts to achieve a palladium-catalyzed hydrogenation failed, we tried other borohydride salts. The use of tetramethylammonium borohydride did not increase the overall yield of $\mathbf{6 n}$, however, a rather substantial improvement was observed when using sodium cyanoborohydride. Indeed, from pure acrylate $\mathbf{2 n}$, a $70 \%$ yield of $\mathbf{6 n}$ was obtained, and in one pot starting from aldehyde $3 \mathbf{n}$, a $48 \%$ overall yield of $\mathbf{6 n}$ was achieved. Moreover, without using an inert atmosphere for the initial condensation between furfural (3n) and ethyl nitroacetate (4) the overall yield of $\mathbf{6 n}$ dropped to $37 \%$ even when using sodium cyanoborohydride. The optimized conditions were then applied to aldehyde $\mathbf{3 r}$ and afforded a significantly improved $46 \%$ yield of $6 \mathbf{r}$, in comparison with our single trial via $5 \mathbf{r}$, which ended up with less than $20 \%$ of an impure sample of $\mathbf{6 r}$. Finally, from the isolated $\alpha$-nitro esters $6 \mathbf{a}-\mathbf{s}$, their reduction into the corresponding $\alpha$-amino esters $\mathbf{1 a}-\mathbf{s}$, using zinc and hydrochloric acid in ethanol usually proceeded in good yield, although care had to be taken during work-up as zinc complexes required the addition of an excess of ammonia to fully break in the course of the extraction.

In an attempt to overcome the lack of condensation between ethyl nitroacetate (4) and electron-poor substrates $\mathbf{5 j} \mathbf{j}-\mathbf{l}$, we focused on the model preparation of the trifluoromethyl-bearing $\alpha$-nitro ester $\mathbf{6 j}$ from acylals $\mathbf{7}$ depicted in Scheme 2. As well reviewed [14], acylals can be prepared from aldehydes and anhydrides using a variety of acids as catalysts. In our case, ${ }^{1} \mathrm{H}$ NMR monitoring of the reaction between 2-(trifluoromethyl)benzaldehyde $(\mathbf{3} \mathbf{j})$ and acetic anhydride using

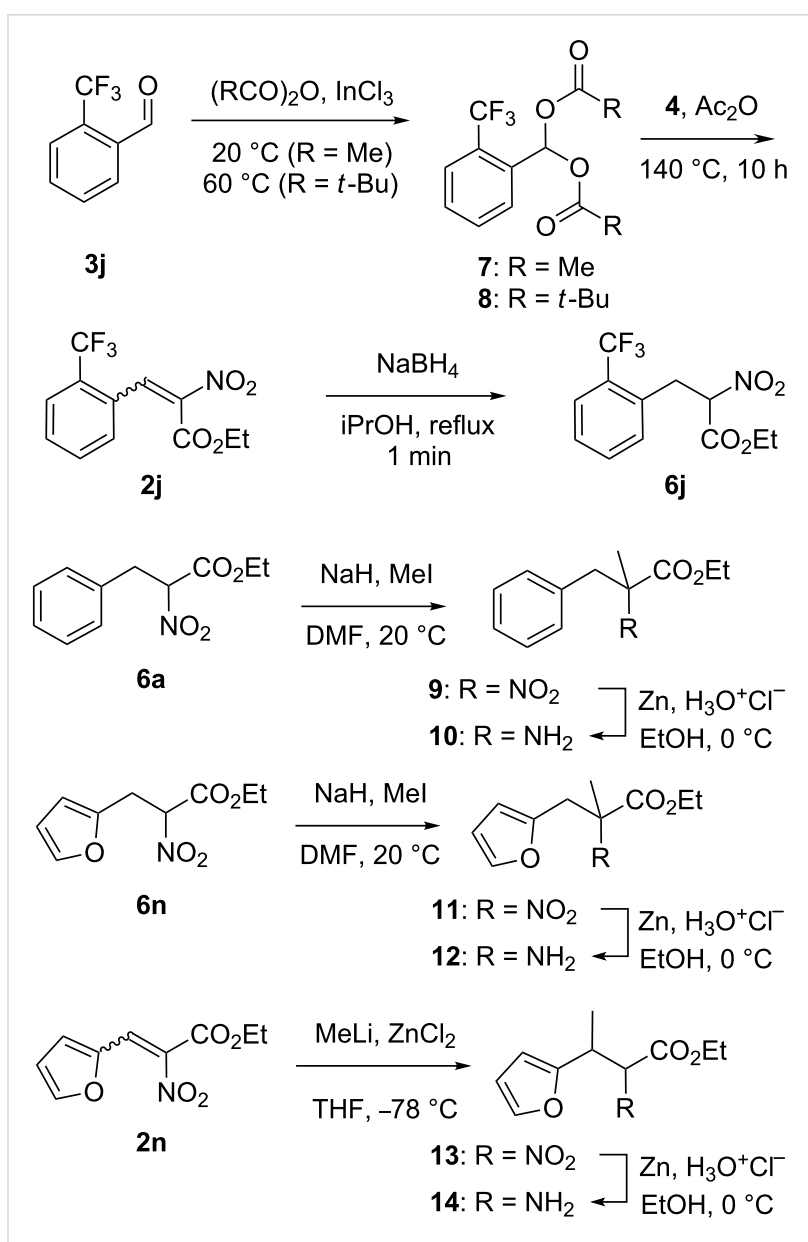

Scheme 2: Preparations of $\alpha$-amino esters 10, 12 and 14.

indium(III) chloride [15] as a Lewis acid catalyst [16] without any solvent at room temperature pointed out a complete conversion into acylal 7 overnight. A similar reaction using pivaloyl anhydride and either indium(III) chloride or tetrafluoroboric acid as a catalyst had to be heated at $60{ }^{\circ} \mathrm{C}$ for a few hours to secure a similar conversion into pivalal 8 . From intermediates 7 and $\mathbf{8}$, and as previously reported in the case of malonates [17-19], we then hoped for an improvement of their condensation with ethyl nitroacetate (4). The ${ }^{1} \mathrm{H}$ NMR monitoring of the reaction between compounds 7 or 8 and ethyl nitroacetate (4) in the presence of a catalytic amount of indium(III) chloride pointed out the occurrence of tangibly more of the expected acrylate $\mathbf{2} \mathbf{j}$, although along with many byproducts. Indeed, in a typical experiment, upon reduction of the crude reaction product obtained from 8 and ethyl nitroacetate (4), a discouraging $13 \%$ yield of the corresponding $\alpha$-nitro ester $\mathbf{6 j}$ was isolated. The use of $\alpha$-nitro esters to obtain disubstituted $\alpha$-amino esters such as compound $\mathbf{1 0}$ via an alkylation step has been described [20]. In order to reach such $\alpha$-amino esters, we tried their preparation via a $\mathrm{C}$-methylation of $\alpha$-nitroester $6 \mathbf{6}$ in DMF using sodium hydride and methyl iodide. Upon purification, this gave 
$46 \%$ of the nitro compound 9 with $94 \%$ purity (as assessed by ${ }^{1} \mathrm{H}$ NMR). Despite this modest yield, the ensuing reduction using zinc and hydrochloric acid in ethanol overnight gave a sufficient amount of the (pure) target phenyl-bearing $\alpha$-amino ester 10 which had been previously obtained by catalytic hydrogenation using palladium [20]. The same transformation sequences were used starting with compound $\mathbf{6 n}$ and provided the furan-bearing $\alpha$-amino ester 12 in $32 \%$ overall yield via the nitro compound 11. We also investigated the reported [4] 1,4addition of a methyl on compound $\mathbf{2 n}$ to prepare the $\beta$-methylated derivative 13. In our hands, a rather modest $43 \%$ yield of the expected adduct $\mathbf{1 3}$ was achieved from purified acrylate $\mathbf{2 n}$. Again, the ensuing reduction of $\mathbf{1 3}$ using zinc and hydrochloric acid gave the target $\alpha$-amino ester $\mathbf{1 4}$ in an $85 \%$ yield.

To avoid the recourse to more rare and/or expensive heterocyclic aldehydes, we also tried synthetic approaches based on $[2+3]$ cycloadditions. As depicted in Scheme 3, the carbon dioxide-producing reaction [21] between two equivalents of ethyl nitroacetate (4) and styrene (15), gave the isoxazoline 16 in a $72 \%$ yield as a latent $\alpha$-amino ester [22-24]. From this compound, a reductive cleavage of the isoxazoline ring was initiated using palladium over charcoal and a large excess of ammonium formate in refluxing ethanol. The analysis of the resulting mixture by LC/MS and ${ }^{1} \mathrm{H}$ NMR pointed out the occurrence of the expected [25] oxime 17 but along with an unexpected sizable proportion of the $\alpha$-amino ester 18. Accordingly, the (filtrated) ethanolic solution was then treated with zinc and hydrochloric acid in ethanol to complete the reduction and the amino ester 18 was isolated in a $72 \%$ yield. In order to illustrate the synthetic potential of the isoxazoline $\mathbf{1 6}$ as an already protected amino acid moiety, we prepared the piperazine-2,5diones 23a,b in four steps. This was achieved by the hydrolysis of the ester function of $\mathbf{1 6}$, followed by its coupling with glycine or phenylalanine ethyl esters (respectively 20a and 20b) using 2-(1H-benzotriazole-1-yl)-1,1,3,3-tetramethylaminium tetrafluoroborate (TBTU) as a coupling agent to give the corresponding amides $\mathbf{2 1 a}, \mathbf{b}$. The isoxazole ring of these compounds was then cleaved using palladium and ammonium formate to give the corresponding oximes which were immediately reduced into amines $\mathbf{2 2 a}, \mathbf{b}$, using zinc and hydrochloric acid, and a thermal cyclization of these crude products gave the piperazine-2,5-diones $\mathbf{2 3 a}, \mathbf{b}$ in, respectively, 31 and $40 \%$ overall yield from compound $\mathbf{1 6}$.

A second [2+3] cycloaddition-based approach is described in Scheme 4. It started with the preparation of the methylene-bearing dipolarophile 25 from propargylamide 24 using gold(I) chemistry, which turned out to be tolerant to a wide variety of dry solvents (dichloromethane, tetrahydrofuran, toluene, dimethylformamide, or acetonitrile) [26,27]. As for a related

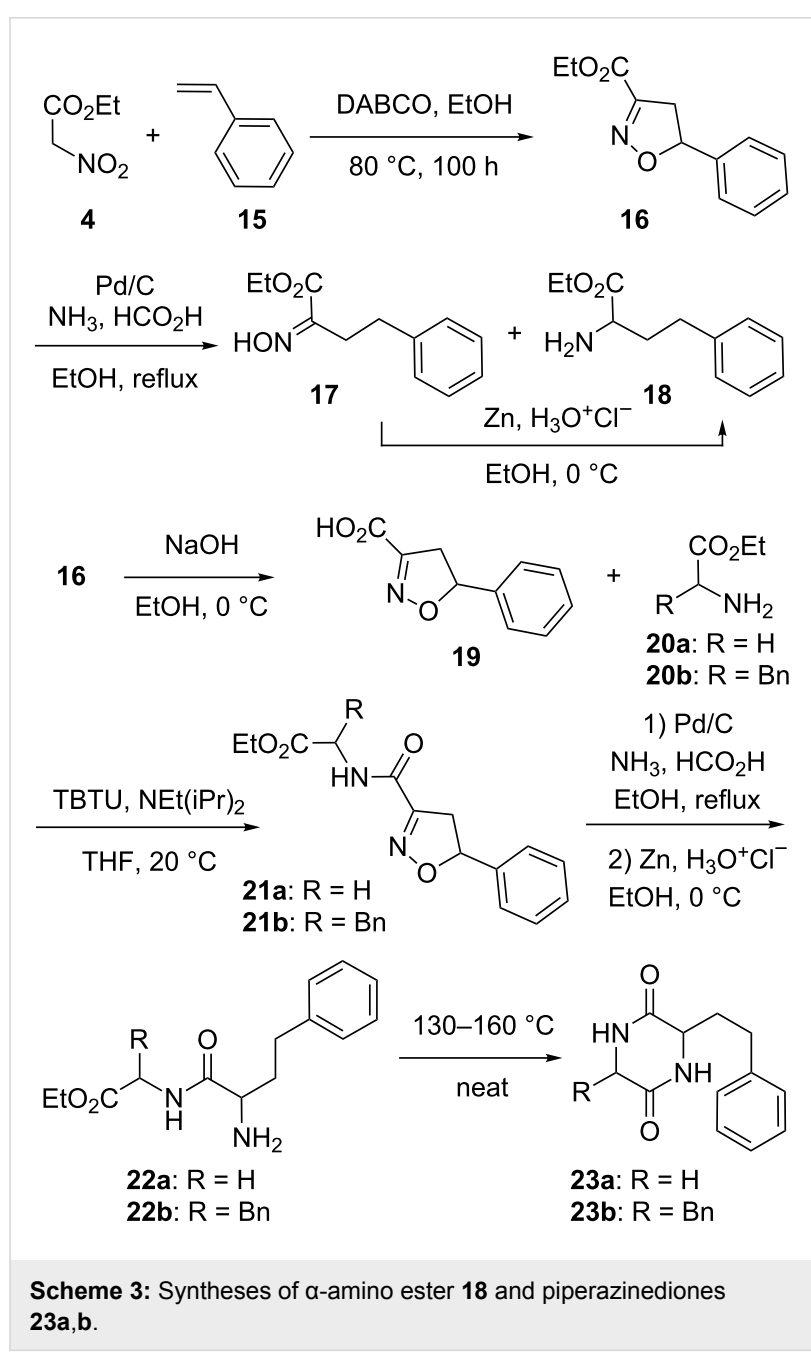

report [28] describing [2+3] cycloadditions between chlorooxime $\mathbf{2 6}$ and other methylene-bearing compounds, its reaction with compound $\mathbf{2 5}$ gave the spiroacetal 27. However, in the present case this cycloadduct was only detectable by ${ }^{1} \mathrm{H}$ NMR analysis of the crude reaction mixture. Indeed, a slow ringopening reaction took place upon standing in solution to mainly give the isoxazole isomer $\mathbf{2 8}$ along with much less of the target oxazole-bearing $\alpha$-hydroximino ester 29. Extensive trials to alter the selectivity of the ring opening using heat, adsorption over silica, acids $\left(\mathrm{BF}_{3} \cdot \mathrm{OEt}_{2}, \mathrm{AcOH}\right)$ or bases $\left(\mathrm{NEt}_{3}, \mathrm{LDA}\right.$, EtONa) all failed to change the ratio of compounds $\mathbf{2 8}$ and $\mathbf{2 9}$, which were isolated in 5 and $28 \%$ yield, respectively. Despite the potential synthetic interest $[29,30]$ of isoxazole $\mathbf{2 8}$, we did not pursue this further, but focused on another approach involving an oxidative addition of ethyl nitroacetate (4) on the methylene-bearing dipolarophiles $\mathbf{2 5}$ mediated by cerium(IV) ammonium nitrate (CAN). This was inspired by reports describing CAN-mediated carbon-carbon bond formation reactions between ethyl nitroacetate (4) and tri-O-acetylglycals $[31,32]$ or other sugar-derived alkenes [33]. We first tried the 


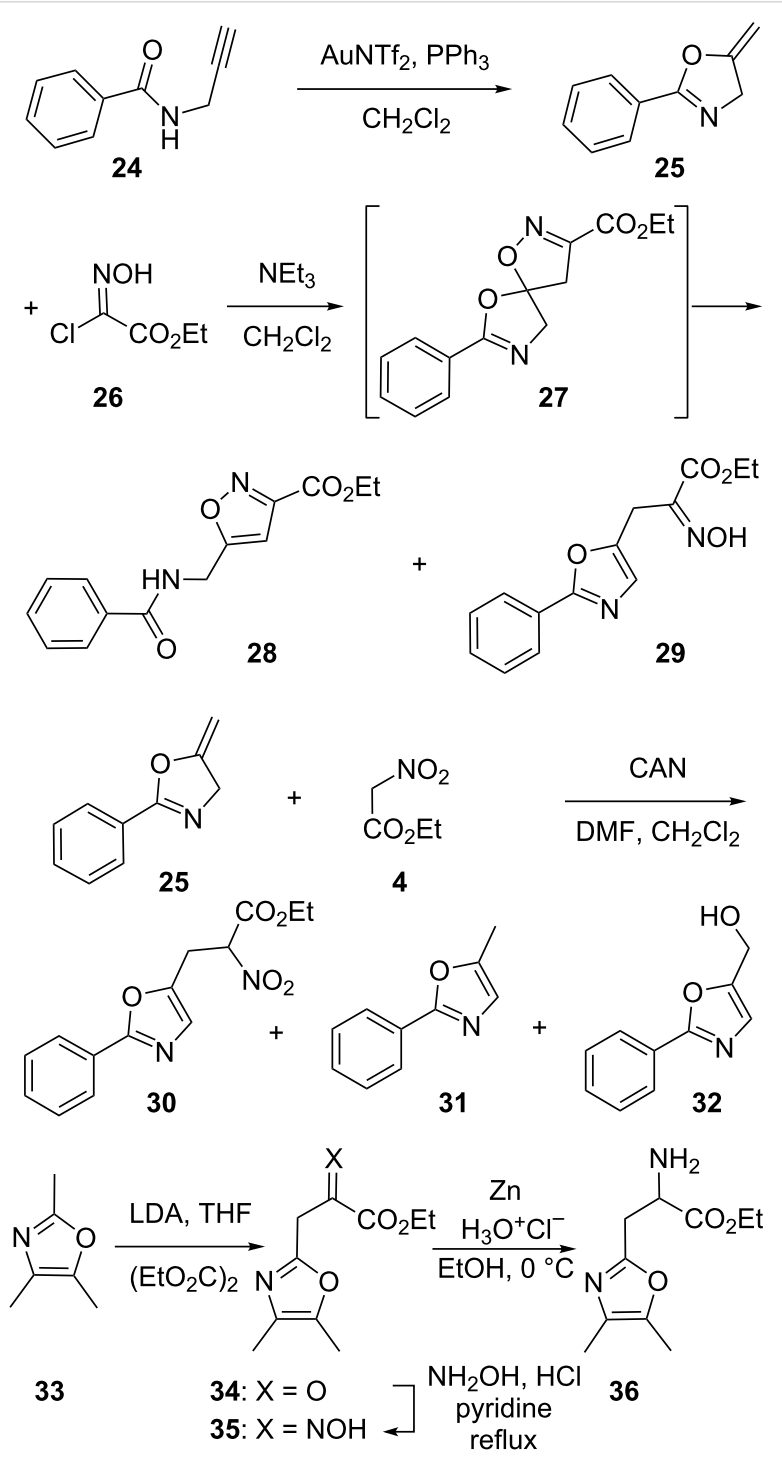

Scheme 4: Syntheses of $\alpha$-hydroximino ester 29 and $\alpha$-amino ester 36.

conditions described in the literature $\left(0{ }^{\circ} \mathrm{C}\right.$, mixture of methanol and dimethylformamide as a solvent), without much success in our case. Quite a few trials followed, changing the solvent to a dichloromethane/dimethylformamide mixture or dimethylformamide alone, or modifying the reaction conditions (at room temperature, $0{ }^{\circ} \mathrm{C}$ or $-20{ }^{\circ} \mathrm{C}$ ), but none resulted in a flagrant improvement. Indeed, as precisely described in the experimental part, the (impure) target nitroester $\mathbf{3 0}$ was isolated once in a disappointing $22 \%$ yield and quite a few byproducts were noticed. A control experiment omitting the ethyl nitroacetate (4) allowed us to identify amongst these: the oxazole derivative $\mathbf{3 1}$ resulting from an isomerization of $\mathbf{2 5}$ as well as alcohol $\mathbf{3 2}$ resulting from an oxidation of compound 25. Accordingly, this greatly dampened our hope to improve this transformation (trials with manganese(III) acetate were not successful either)
We then resorted to a different approach to prepare the oxazolebearing $\alpha$-amino ester 36 from 2,4,5-trimethyloxazole (33). Deprotonation of this compound was achieved using lithium diisopropylamide (LDA) and this was followed by the addition of diethyl oxalate to give a mixture of compounds including the ketoester 34. Then, treatment of this mixture with hydroxylamine allowed the isolation of the target $\alpha$-hydroximino ester 35 in a $7 \%$ overall yield. Two dimensional NMR experiments confirmed the depicted structure for compound $\mathbf{3 5}$ and trace amounts of the other isomers were detected in other chromatographic fractions but could not be fully purified. In any case, from the $\alpha$-hydroximino ester $\mathbf{3 5}$, a reduction using zinc and hydrochloric acid gave the target oxazole-bearing $\alpha$-amino ester 36.

Finally, as depicted in Scheme 5, the oxazole-bearing $\alpha$-amino ester $\mathbf{4 3}$ was prepared from the aspartic acid derivative $\mathbf{3 7}$ through the propargylamide $\mathbf{3 8}$ followed by a gold(I)-catalyzed cyclization to form the oxazoline derivative $\mathbf{4 0}$. Concerning the amidation step, propargylamide $\mathbf{3 8}$ was obtained in $78 \%$ yield provided that an excess of triethylamine was avoided (otherwise, as determined by a control experiment, substantial amounts of the relatively stable succinyl derivative 39 [34] resulting from a triethylamine-triggered cyclization of $\mathbf{3 8}$ were isolated) [35-37]. The treatment of compound $\mathbf{3 8}$ with a catalytic amount of gold(I) in warm toluene provided us with the oxazoline $\mathbf{4 0}$ in an $80 \%$ yield. However, this compound turned out to be unstable, either on standing, probably because of an autoxidation, as reported in other instances [27], or in $\mathrm{CDCl}_{3}$, probably because of acid traces. To achieve its isomerization, a literature search pointed out the use of an excess of DBU and heat $[38,39]$. However, boiling compound $\mathbf{4 0}$ in toluene in the presence of an excess of DBU led, after chromatography, to only

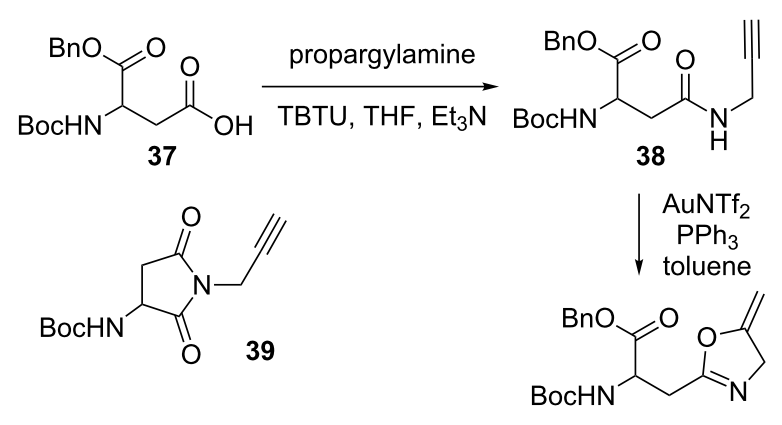

40

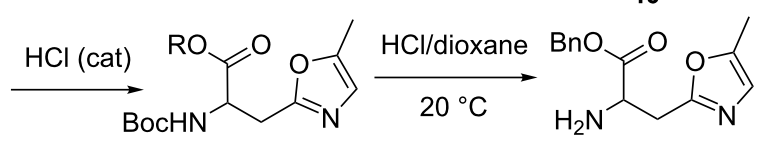

41: $\mathrm{R}=\mathrm{Bn}\left(\mathrm{DBU}\right.$, toluene, $\left.80^{\circ} \mathrm{C}\right)$

42: $\mathrm{R}=\mathrm{Et}\left(\mathrm{DBU}, \mathrm{EtOH}, 110^{\circ} \mathrm{C}\right)$

43 
$24 \%$ of the benzyl ester 41 . Since, amongst few side reactions, we suspected a benzylester cleavage, we undertook this reaction under argon in ethanol at $110{ }^{\circ} \mathrm{C}$ using a microwave reactor along with only one equivalent of DBU and these changes provided us with the ethyl ester $\mathbf{4 2}$ in a 51\% yield. Finally, a far more simple procedure was found by just adding a catalytic amount of hydrogen chloride in 1,4-dioxane to the toluene solution containing compound 40. This afforded, after overnight stirring, the isomerized compound $\mathbf{4 1}$ in a $69 \%$ yield. Finally, the deprotection of the amine function was achieved with the use of an excess of hydrogen chloride in 1,4-dioxane to give the target $\alpha$-amino ester $\mathbf{4 3}$.

\section{Conclusion}

In the course of our attempts to extend the use of ethyl nitroacetate (4) to prepare $\alpha$-amino ethyl esters via condensation reactions with aldehydes $\mathbf{3}$ or dimethylacetals $\mathbf{5}$, some severe limitations were encountered. Indeed, the ubiquitous occurrence of aryl methyl esters, arising from an unwanted O-alkylation of ethyl nitroacetate (4), plagued all our efforts to improve the latter synthetic pathway [2]. This side reaction pretty much limited the approach to electron-rich substrates and even our attempts to use the acylals $\mathbf{7}$ or $\mathbf{8}$, easily made from 2-trifluoromethylbenzaldehyde (3j), were very moderately successful. Such phenomenon probably accounts for the modest yields reported in many instances even when using titanium tetrachloride to achieve this condensation $[5,6]$. Concerning the reduction of the nitroacrylates 2 into the $\alpha$-nitro esters $\mathbf{6}$, tangible but still modest yield improvements were observed when using sodium cyanoborohydride instead of sodium borohydride in some cases. This actually illustrates the sensitivity of this reduction which, along with the condensation, are quite limiting. As described above, the recourse to cycloadditionbased approaches allowed us to explore some original chemistry aiming at the preparation of oxazole-bearing $\alpha$-amino esters which was of interest per se. Indeed, the previously unreported acid-catalyzed conditions to achieve the isomerization of the methylene-bearing oxazoline $\mathbf{4 0}$ into oxazole $\mathbf{4 1}$ should be useful in many other instances. In any case, as described in a following report [40], to overcome some of the limitations described here, we then focused on an exhaustive investigation of malonate-based strategies and reached an even more diverse set of $\alpha$-amino esters.

\section{Supporting Information}

\section{Supporting Information File 1}

Experimental and copies of spectra.

[https://www.beilstein-journals.org/bjoc/content/

supplementary/1860-5397-14-263-S1.pdf]

\section{Acknowledgements}

This work was supported by the Agence Nationale de la Recherche (ANR), grant ANR-11-CRNT-0004, in the context of the investment program 'GLOBAL CARE', an association of the Instituts Carnot 'Pasteur-Maladies Infectieuses', 'CurieCancer', 'Voir et Entendre', 'Institut du Cerveau et de la moelle Épinière' and the 'Consortium pour l'Accélération de l'Innovation et de son Transfert dans le domaine du Lymphome' (CALYM). This project also benefited from the Valoexpress funding call of the Institut Pasteur. Prof. Christian Bréchot, Dr. Muriel Delepierre and Dr. Daniel Larzul, from the Institut Pasteur are acknowledged for their interest and support.

\section{ORCID ${ }^{\circledR}$ iDs}

Glwadys Gagnot - https://orcid.org/0000-0002-5778-995X

Eloi P. Coutant - https://orcid.org/0000-0002-5571-7442

Yves L. Janin - https://orcid.org/0000-0003-3019-9842

\section{References}

1. Coutant, E. P.; Janin, Y. L. Chem. - Eur. J. 2015, 21, 17158-17171. doi:10.1002/chem.201501531

2. Hervin, V. O.; Coutant, E. P.; Gagnot, G.; Janin, Y. L. Synthesis 2017, 49, 4093-4110. doi:10.1055/s-0036-1589506

3. Lehnert, W. Tetrahedron 1972, 28, 663-666. doi:10.1016/0040-4020(72)84029-8

4. Fornicola, R. S.; Oblinger, E.; Montgomery, J. J. Org. Chem. 1998, 63, 3528-3529. doi:10.1021/jo980477h

5. Nakamura, S.; Uchiyama, M.; Ohwada, T. J. Am. Chem. Soc. 2003, 125, 5282-5283. doi:10.1021/ja0343151

6. Nakamura, S.; Sugimoto, H.; Ohwada, T. J. Am. Chem. Soc. 2007, 129, 1724-1732. doi:10.1021/ja067682w

7. Kochetkov, K. A.; Babievskii, K. K.; Belikov, V. M.; Garbalinskaya, N. S.; Bakhmutov, V. I. Bull. Acad. Sci. USSR, Div. Chem. Sci. (Engl. Transl.) 1980, 29, 458-461. doi:10.1007/bf00949634

8. Kochetkov, K. A.; Babievskii, K. K.; Nalivaiko, E. V.; Garbalinskaya, N. S.; Belikov, V. M. Bull. Acad. Sci. USSR, Div. Chem. Sci. (Engl. Transl.) 1981, 30, 466-469. doi:10.1007/bf00949597

9. Meyers, A. I.; Sircar, J. C. J. Org. Chem. 1967, 32, 4134-4136. doi:10.1021/jo01287a116

10. Lehnert, W. Synthesis 1976, 827-829. doi:10.1055/s-1976-24226

11. Sinhababu, A. K.; Borchardt, R. T. Tetrahedron Lett. 1983, 24 , 227-230. doi:10.1016/s0040-4039(00)81371-4

12. Dauzonne, D.; Royer, R. Synthesis 1987, 399-401. doi:10.1055/s-1987-27962

13. Fioravanti, S.; Pellacani, L.; Vergari, M. C. Org. Biomol. Chem. 2012, 10, 524-528. doi:10.1039/c1ob06260c

14. Yin, L.; Zhang, Z.-H.; Wang, Y.-M. Tetrahedron Lett. 2007, 48, 3119-3122. doi:10.1016/j.tetlet.2007.01.007

15. Yadav, J. S.; Reddy, B. V. S.; Srinivas, C. Synth. Commun. 2002, 32, 1175-1180. doi:10.1081/scc-120003607

16. Aggarwal, V. K.; Fonquerna, S.; Vennall, G. P. Synlett 1998, 849-850. doi:10.1055/s-1998-1799

17. Trost, B. M.; Vercauteren, J. Tetrahedron Lett. 1985, 26, 131-134. doi:10.1016/s0040-4039(00)61861-0 
18. Ogiwara, Y.; Takahashi, K.; Kitazawa, T.; Sakai, N. J. Org. Chem. 2015, 80, 3101-3110. doi:10.1021/acs.joc.5b00011

19. Li, Z.; Duan, Z.; Wang, H.; Tian, R.; Zhu, Q.; Wu, Y. Synlett 2008, 2535-2539. doi:10.1055/s-2008-1078216

20. Harel, T.; Rozen, S. J. Org. Chem. 2007, 72, 6500-6503. doi:10.1021/jo0709450

21. Leslie-Smith, M. G.; Paton, R. M.; Webb, N. Tetrahedron Lett. 1994, 49, 9251-9254. doi:10.1016/0040-4039(94)88480-3

22. Cecchi, L.; De Sarlo, F.; Machetti, F. Tetrahedron Lett. 2005, 46, 7877-7879. doi:10.1016/j.tetlet.2005.09.110

23. Cecchi, L.; De Sarlo, F.; Machetti, F. Eur. J. Org. Chem. 2006, 4852-4860. doi:10.1002/ejoc.200600475

24. Griffioen, G.; Van Doorren, T.; Rojas de la Parra, V.; Marchand, A.; Allasia, S.; Kilonda, A.; Chaltin, P. Indole amide derivatives and related compounds for use in the treatment of neurodegenerative diseases. PCT Patent Application WO/2010/142801 A1, Dec 16, 2010.

25. Auricchio, S.; Ricca, A. Tetrahedron 1987, 43, 3983-3986. doi:10.1016/s0040-4020(01)81680-x

26. Weyrauch, J. P.; Hashmi, A. S. K.; Schuster, A.; Hengst, T.; Schetter, S.; Littmann, A.; Rudolph, M.; Hamzic, M.; Visus, J.; Rominger, F.; Frey, W.; Bats, J. W. Chem. - Eur. J. 2010, 16, 956-963. doi:10.1002/chem.200902472

27. Hashmi, A. S. K.; Blanco Jaimes, M. C.; Schuster, A. M.; Rominger, F. J. Org. Chem. 2012, 77, 6394-6408. doi:10.1021/jo301288w

28. Bantreil, X.; Vaxelaire, C.; Godet, T.; Parker, E.; Sauer, C.; Belmont, P. Org. Biomol. Chem. 2011, 9, 4831-4841. doi:10.1039/c1ob05354j

29. Mioskowski, C.; De Lamo Marin, S.; Maruani, M.; Gill, M. Analogs of 4-hydroxyisoleucine and uses thereof. U.S. Patent Application 2006/0199853 A1, Sept 7, 2006.

30. Mioskowski, C.; Wagner, A.; De Lamo Marin, S.; Catala, C.; Becht, J. M. Method for preparing 4-hydroxyisoleucine diastereoisomers and enantiomers and derivatives thereof. PCT Patent Application WO2004/052836 A, June 24, 2004.

31. Sommermann, T.; Kim, B. G.; Peters, K.; Peters, E.-M.; Linker, T. Chem. Commun. 2004, 2624-2625. doi:10.1039/b410120k

32. Elamparuthi, E.; Kim, B. G.; Yin, J.; Maurer, M.; Linker, T. Tetrahedron 2008, 64, 11925-11937. doi:10.1016/j.tet.2008.08.109

33. Kim, B. G.; Schilde, U.; Linker, T. Synthesis 2005, 1507-1513. doi:10.1055/s-2005-865325

34. Barra, M.; Roy, O.; Traikia, M.; Taillefumier, C. Org. Biomol. Chem. 2010, 8, 2941-2955. doi:10.1039/b923275c

35. Matsoukas, J.; Cordopatis, P.; Theodoropoulos, D. J. Org. Chem. 1977, 42, 2105-2108. doi:10.1021/jo00432a017

36. Schön, I.; Szirtes, T.; Rill, A.; Balogh, G.; Vadász, Z.; Seprődi, J.; Teplán, I.; Chino, N.; Yoshizawa Kumogaye, K.; Sakakibara, S. J. Chem. Soc., Perkin Trans. 1 1991, 3213-3223. doi:10.1039/p19910003213

37. Flaih, N.; Gadjou, C.; Lafont, O.; Galons, H. Synlett 2000, 896-898. doi:10.1055/s-2000-6701

38. Tiecco, M.; Testaferri, L.; Tingoli, M.; Marini, F. J. Org. Chem. 1993, 58, 1349-1354. doi:10.1021/jo00058a011

39. Bull, R. J.; Ray, N. C. 2-(9H-Xanthen-9-yl)-oxazol derivatives as m3 muscarinic receptor antagonists for the treatment of asthma and chronic obstructive lung disease. PCT Patent Application WO 2009/098455 A1, Aug 13, 2009.

40. Coutant, E. P.; Hervin, V.; Gagnot, G.; Ford, C.; Baatallah, R.; Janin, Y. L. Beilstein J. Org. Chem. 2018, 14, 2853-2859. doi:10.3762/bjoc. 14.264

\section{License and Terms}

This is an Open Access article under the terms of the Creative Commons Attribution License (http://creativecommons.org/licenses/by/4.0). Please note that the reuse, redistribution and reproduction in particular requires that the authors and source are credited.

The license is subject to the Beilstein Journal of Organic Chemistry terms and conditions: (https://www.beilstein-journals.org/bjoc)

The definitive version of this article is the electronic one which can be found at: doi:10.3762/bjoc. 14.263 